\title{
Human parvovirus PARV4 DNA in tissues from adult individuals: a comparison with human parvovirus B19 (B19V)
}

\author{
Fabiana Corcioli ${ }^{1}$, Krystyna Zakrzewska ${ }^{1}$, Rosa Fanci ${ }^{2}$, Vincenzo De Giorgi ${ }^{3}$, Massimo Innocenti ${ }^{4}$, Matteo Rotellini ${ }^{5}$,
} Simonetta Di Lollo ${ }^{5}$, Alberta Azzi ${ }^{* *}$

\begin{abstract}
Background: PARV4 is a new member of the Parvoviridae family not closely related to any of the known human parvoviruses. Viremia seems to be a hallmark of PARV4 infection and viral DNA persistence has been demonstrated in a few tissues. Till now, PARV4 has not been associated with any disease and its prevalence in human population has not been clearly established. This study was aimed to assess the tissue distribution and the ability to persist of PARV4 in comparison to parvovirus B19 (B19V).
\end{abstract}

Results: PARV4 and B19V DNA detection was carried out in various tissues of individuals without suspect of acute viral infection, by a real time PCR and a nested PCR, targeting the ORF2 and the ORF1 respectively. Low amount of PARV4 DNA was found frequently $(>40 \%)$ in heart and liver of adults individuals, less frequently in lungs and kidneys (23,5 and 18\% respectively) and was rare in bone marrow, skin and synovium samples $(5,5 \%, 4 \%$ and $5 \%$, respectively). By comparison, B19V DNA sequences were present in the same tissues with a higher frequency (significantly higher in myocardium, skin and bone marrow) except than in liver where the frequency was the same of PARV4 DNA and in plasma samples where B19V frequency was significantly lower than that of PARV4

Conclusions: The particular tropism of PARV4 for liver and heart, here emerged, suggests to focus further studies on these tissues as possible target for viral replication and on the possible role of PARV4 infection in liver and heart diseases. Neither bone marrow nor kidney seem to be a common target of viral replication.

\section{Background}

PARV4 is a member of the Parvoviridae family discovered in 2005 in plasma from an intravenous drug user, with symptoms consistent with acute HIV infection, but confirmed to be HIV RNA negative [1]. It seemed to be not closely related to any of the known human or animal parvoviruses until 2008 when novel porcine and bovine parvoviruses highly similar to PARV4 were identified so that it was proposed the inclusion of PARV4 in a new genus Hokovirus [2]. Three genotypes of PARV4 have been identified at present $[3,4]$. Till now, it has not been associated with any disease and its spread in the human population has not been clearly assessed. In fact, the serological assays for anti-PARV4 antibody

\footnotetext{
* Correspondence: alberta.azzi@unifi.it

1 Department of Public Health, University of Firenze, Viale Morgagni 48, Firenze, Italy

Full list of author information is available at the end of the article
}

detection, only recently developed, till now have been applied on small groups of individuals only [5]. Viremia seems to be a hallmark of PARV4 infection. PARV4 was found in $5 \%$ of plasma pools at levels suggesting the existence of donations with high viral load [6], in 16\% of clotting factor VIII concentrates [7], in 2\% of plasma samples from healthy donors [8] and in 7,95\% of serum samples from intravenous drug users in Thailand [9]. Several data indicate that the transmission of the virus predominantly occurs by parenteral route $[5,10]$ whereas the respiratory transmission seems to be unlikely [11]. As regards tissue distribution, PARV4 DNA was demonstrated frequently in bone marrow and lymphoid tissue from HIV infected individuals [12] and also in liver of non HIV-infected adults [13]. One study reports that PARV4 DNA can be detected, with a low frequency, in healthy and pathological skin samples [14]. 
It is known that $\mathrm{B} 19 \mathrm{~V}$ frequently persist in solid tissues in asymptomatic individuals and, less frequently, also in bone marrow [15].

The aim of this study was to assess whether PARV4 is able to persist in different tissues, like B19V, or if it shows a particular tissue tropism.

\section{Results}

With the aim to assess the tissue distribution and the ability to persist of PARV4 in comparison to B19V, we searched for DNA sequences of both parvoviruses in various tissues of individuals without suspect of acute viral infection. Table 1 shows the results of PARV4 DNA detection in different tissues, in comparison with B19 DNA detection. The frequency of PARV4 DNA finding was low in skin, synovium and bone marrow (4$5,5 \%)$ whereas in myocardium samples PARV4 sequences were shown in 17 out of 35 (49\%), a frequency significantly higher than in the other tissues examined but significantly lower than that of B19V. PARV4 DNA was found in 8 out of 39 plasma specimens $(20,5 \%)$ while B19V DNA was demonstrated in one of these specimens only $(2,5 \%)$. It is noteworthy that these 39 specimens were from 21 immunodepressed hematological patients and 18 immunocompetent individuals and the frequency of viremia was 33\% (7 positives out of 21 ) in the former group and 5,5\% (1 positive out of 18) in the second group (however, this difference is not statistically significant). The viral load in these sera was low: below $3,8 \times 10^{3}$ copies $/ \mathrm{ml}$.

From 17 out the 35 individuals dead for various causes, without known viral myocarditis or dilated cardiomyopathy, lungs, liver, kidney and blood specimens could be examined, in addition to the myocardium, with the aim to verify the distribution of PARV4 and B19V DNA in the different organs of the same individual. In none of these cases viral DNA was detectable in the blood while PARV4 as well as B19V DNA were found frequently in the different organs analyzed (Table 2). PARV4 DNA was present more frequently in the liver

Table 1 Detection of PARV4 DNA in tissues and plasma in comparison with B19 DNA in the same specimens*

\begin{tabular}{|c|c|c|c|}
\hline Samples & $\mathbf{N}^{\circ}$ & $\begin{array}{l}\text { PARV4 DNA positive } \\
(\%)\end{array}$ & $\begin{array}{l}\text { B19V DNA positive } \\
(\%)\end{array}$ \\
\hline Bone marrow $^{\circ}$ & 26 & $2(5,5)$ & $9(25)$ \\
\hline Skin $^{\circ}$ & 25 & $1(4)$ & $18(72)$ \\
\hline Sinovyum & 21 & $1(5)$ & $6(28,5)$ \\
\hline Myocardium $^{\circ}$ & 35 & $17(49)$ & $26(74)$ \\
\hline Plasma $^{\circ}$ & 39 & $8(20,5)$ & $1(2,5)$ \\
\hline
\end{tabular}

Table 2 Detection of PARV4 and B19V DNA in different tissues from 17 individuals without known viral myocarditis or dilated cardiomyopathy

\begin{tabular}{ccccccccc}
\hline & \multicolumn{2}{c}{ myocardium } & \multicolumn{2}{c}{ lung } & \multicolumn{2}{c}{ liver } & \multicolumn{2}{c}{ kidney } \\
\hline Patient & PARV4 & B19V & PARV4 & B19V & PARV4 & B19V & PARV4 & B19V \\
\hline 1 & - & + & - & - & - & - & - & - \\
2 & - & - & - & - & - & - & - & - \\
3 & + & + & - & + & - & - & - & + \\
4 & - & + & - & - & - & - & - & - \\
5 & - & + & - & + & - & - & - & + \\
6 & + & + & - & + & - & - & + & - \\
7 & + & + & + & + & + & + & - & + \\
8 & + & + & - & - & + & - & - & - \\
9 & - & - & - & - & + & - & + & - \\
10 & + & + & + & + & + & + & - & + \\
11 & - & + & + & + & + & + & - & + \\
12 & + & + & - & + & + & + & - & + \\
13 & - & + & - & - & - & - & - & - \\
14 & - & + & - & - & - & + & - & - \\
15 & + & - & + & - & + & - & + & - \\
16 & - & + & - & - & - & + & - & + \\
17 & - & + & - & - & - & + & - & + \\
\hline Tot & $7(41)$ & 14 & $4(23)$ & 7 & $7(41)$ & 7 & $3(18)$ & 8 \\
& & $(82)$ & & $(41)$ & & $(41)$ & & $(47)$ \\
\hline
\end{tabular}

* number of positives (\%)

and in the myocardium (41\%) than in lungs and kidneys (23,5\% and $18 \%$ respectively). The frequency of PARV4 DNA in the liver was similar to that of B19V DNA in this tissue and lower in the others. In one individual PARV4 DNA and in 4 individuals B19V DNA were demonstrated in myocardium samples only. In one individual PARV4 DNA and in 4 individuals B19V DNA were present in all the tissues examined. In two cases PARV4 DNA sequences were not demonstrable in the myocardium and were detectable in other tissues, whereas B19V infected individuals had always DNA sequences in the myocardium.

The concentration of PARV4 DNA in all the positive tissues was generally low, below or near the level of quantization by the real time PCR here employed, corresponding to $\leq 380$ copies $/ 10^{6}$ cells.

As previously reported, the copy number of $\mathrm{B} 19 \mathrm{~V}$ DNA varied from below the level of quantization by the real time PCR to $7 \times 10^{4}$ copies per $10^{6}$ cells, except for two myocardium samples where about $10^{6}$ copies per $10^{6}$ cells were found (15).

PARV4 sequence analysis, aimed to establish the genotype of PARV4 present in the myocardium samples, could be performed on 10 isolates only, out of 17 positive samples, because of the low level of viral DNA. All were included in the genotype 2 (PARV5) after comparison with consensus sequences of the three genotypes 
(GenBank accession numbers HQ245657-HQ245666). As regards $\mathrm{B} 19 \mathrm{~V}$, either genotype 1 or genotype 2 were present, with a slightly higher frequency of the 2 .

PARV4 DNA was undetectable in the urine specimens of the bone marrow transplantation patients.

\section{Discussion and Conclusions}

In this study low amount of PARV4 DNA was found frequently $(>40 \%)$ in heart and liver of adults individuals, less frequently in lungs and kidneys (23,5 and $18 \%$ respectively) and was rare in bone marrow, skin and synovium samples (5,5\%, $4 \%$ and $5 \%$, respectively). By comparison, B19V DNA was present in the same tissues with a higher frequency (significantly higher in myocardium, skin and bone marrow) except than in liver where its frequency was the same of PARV4 DNA and in plasma samples where B19V frequency was significantly lower than that of PARV4. Some of these results are fairly in agreement with the literature where the frequency of PARV4 DNA in bone marrow varies from $0 \%(0 / 8)$ in HIV uninfected individuals (like the patients enrolled in this study), to $46 \%$ and $65 \%$ in HIV infected patients $[12,16]$ and is $7,7 \%$ in the skin of HIVnegative individuals [14]. The frequency of PARV4 DNA in the liver reported in literature [13] was lower (15\%) in comparison with $41 \%$ in this study. It is to note that the study of Schneider [13] and the present study are very different as regards the number and the source of the specimens analyzed as well as the methods used for PARV4 DNA detection; in fact in the former study 87 liver specimens, obtained mainly in occasion of liver transplantation for various causes, were analyzed by four PCRs. The presence of PARV4 DNA in myocardium samples is reported here for the first time and with a high frequency. The viral load was low also in this tissue and 10 isolates out of the 17 positive myocardium samples that could be analyzed by sequencing showed to be genotype 2 (PARV5), a result that could be related with the age of these patients, all born before 1956 [12], in agreement also with B19V genotype distribution, as previously discussed [15].

Low level PARV4 viremia, which seems characteristic of persistent more than of acute infection, was more common in hematological immunodepressed patients (33\%), in comparison with $5.5 \%$ in immunocompetent individuals. This result, if confirmed on a larger number of patients, could indicate that reactivation or persistence of PARV4 may occur under immunodepression conditions and manifest as viremia more frequently than B19V. In fact, B19V viremia was not reported in this group of hematological immunodepressed patients. Considering that PARV4 DNA was found in bone marrow from 2 out of 36 hematological patients only $(5,5 \%)$ whereas viremia occurred in 7 out of $21(33 \%)$ patients of the same group, these results could suggest that it is unlikely that the site of latency/persistence and reactivation of this virus is the bone marrow. In fact, the two bone marrow positive patients were also PARV4 DNA plasma positive, but at least for the other 5 plasma positive samples another source of viremia has to be hypothesized. On this point, the failure to detect urinary PARV4 shedding in the small group of bone marrow transplantation patients enrolled in this study seems indicate that viral reactivation in the kidney do not occur commonly. In addition, the failure to detect PARV4 DNA in BAL [14] seems indicate that lung is not a site of viral active infection, despite the presence of PARV4 sequences in $23 \%$ of individuals, as our results show. Further studies are necessary to detect the tissue target of PARV4 infection and the results here reported could suggest to focus in particular on the liver.

If more than $40 \%$ of individuals may have viral DNA sequences in liver or myocardium the parenteral route may not be the only way of PARV4 transmission. However, in agreement with the absence of respiratory transmission, it seems likely that PARV4 infection is less frequently transmitted than $\mathrm{B} 19 \mathrm{~V}$ infection and then it is less frequently detectable in the host tissues. When PARV4 infection occurs, the virus spreads to various organs where it can persist, more or less frequently. If confirmed, the observation that the frequency of PARV4 DNA persistence in the liver is of the same order than that of B19 DNA, while in all the other tissues here considered is lower, could indicate that the liver is a main target of PARV4 infection. Its particular tropism for myocardium and liver, here reported, suggests to further study the possible role of PARV4 infection in heart and liver diseases, considering also that PARV4 infection has been frequently detected in HCV infected patients. It is to note that also $\mathrm{B} 19 \mathrm{~V}$ is frequently detectable in liver and myocardial tissue both in acute and persistent B19V infection and its importance in liver and heart diseases still remains unclear [17-21].

\section{Methods}

\section{Clinical samples}

Tissue biopsies were collected in 2006, from 72 Italian adult patients, non HIV-infected, after informed consent: twenty six bone marrow samples from patients (mean age 60; range: 22-82) with B19-unrelated hematological disorders referred to the Department of Hematology, submitted to different chemotherapeutic regimens; twenty one synovial tissue samples from healthy individuals (mean age:70, range:36-82) who underwent surgery for arthrosis or joint trauma, referred to the Department of Orthopedics and Traumatology; twenty five skin biopsies from patients (mean age: 67, 
range 33-93) with B19-unrelated dermatological lesions, referred to the Department of Dermatological Sciences. All the patients were immunocompetent except those with hematological disorders. From 39 out of the 72 patients a serum sample was collected at the same time of the biopsy. In addition, from 2006 to 2010, myocardium autoptic samples were obtained from 35 Italian individuals, non HIV-infected (mean:70, range: 53-84) without known viral myocarditis or dilated cardiomyopathy. From 17 out of 35 cadavers autoptic samples from lungs, liver, kidney and blood were also available. In addition, 93 urine specimens from 29 bone marrow transplantation recipients, at different times after infusion were obtained for PARV4 DNA detection.

\section{PARV4 DNA detection and sequencing}

After DNA extraction using the High Pure PCR Template Preparation Kit (Roche, Basel, Switzerland) PARV4 DNA detection was performed by two PCR able to amplify sequences of the three genotypes. A real time PCR using the primers PVORF2F and PVORF2R reported by Fryer (8) and Syber Green as intercalating dye, was developed for virus detection and viral load assessment. One $\mu \mathrm{l}(25 \mathrm{pmol})$ of each primer and $5 \mu \mathrm{l}$ of extracted DNA were added to $18 \mu \mathrm{l}$ of Quantitec SYBR Green PCR Master Mix (Qiagen, Hilden, Germany). A first step of $10 \mathrm{~min}$ at $94^{\circ} \mathrm{C}$, to activate the Taq polymerase, was followed by 40 cycles of $94^{\circ} \mathrm{C}$ for $30 \mathrm{~s}, 62^{\circ} \mathrm{C}$ for $30 \mathrm{~s}, 72^{\circ} \mathrm{C}$ for $60 \mathrm{~s}$, with a reading step at $79^{\circ} \mathrm{C}$ for $15 \mathrm{~s}$. The reaction was performed using the Rotor-Gene 3000 real time apparatus (Corbett Research, Sidney, Australia).

Melting curve analysis was performed to control the specificity of the PCR products.

To construct the calibration curve, serial dilutions of the target sequence, $268 \mathrm{bp}$ long, cloned in the p-GEM$\mathrm{T}$ vector system (Promega, Milano, Italy) were used. The range of linearity of the quantitative reaction was $1,96 \times 10^{1}-1,96 \times 10^{6}$ copies $/ \mathrm{ml}$. A real time PCR for the $\beta$-globin gene was performed to calculate the number of cells of the tissues extracted, as already described [15]. About 50.000 cells per reaction were analyzed. In addition, a nested PCR described in literature [8], with primers targeting a conserved region of ORF1 of the three known PARV4 genotypes was used to confirm the results of the previous assay.

The sensitivity of these two assays was similar, both being able to detect 2 copies of its target/ $\mu$ in $100 \%$ of cases.

A sample was considered PARV4 DNA positive if positive by both reactions.

Amplicons obtained by the real time PCR (ORF2) and by the nested PCR (ORF 1) were sequenced using the primers PVORF2F and PVORF2R and the inner primers, respectively. Sequencing was carried out by the dideoxynucleotide chain termination method on an ABI Prism 377 automatic sequencer (Applied Biosystems), using the ABI PRISM Dye Terminator cycle sequencing Ready Reaction kit.

B19 DNA detection and genotyping was performed as previously described [15].

\section{Statistical analysis}

The frequencies of PARV4 and B19V DNA positive samples were compared by the chi-square test with Yates correction.

\section{Acknowledgements}

This study was partially supported by a grant from the Foundation "Istituto di Ricerca Virologica Oretta Bartolomei Corsi" (Florence, Italy)

\section{Author details}

${ }^{1}$ Department of Public Health, University of Firenze, Viale Morgagni 48, Firenze, Italy. ${ }^{2}$ Department of Hematology, University of Firenze, Viale Morgagni 85 , Firenze, Italy. ${ }^{3}$ Department of Dermatological Sciences, University of Firenze, Viale Morgagni 85, Firenze, Italy. ${ }^{4}$ Department of Orthopedics, Traumatology, Plastic surgery and Rehabilitation, University of Firenze, Viale Morgagni 85, Firenze, Italy. ${ }^{5}$ Department of Human Pathology, University of Firenze, Viale Morgagni 85, Firenze, Italy.

\section{Authors' contributions}

FC participated in planning of the study and carried out the assays for qualitative and quantitative PARV4 and B19V DNA detection and for sequencing. $K Z$ participated in planning of the study and helped in editing the manuscript. RF, VDG, MI, MR and SDL provided clinical samples. AA conceived and planned the study and wrote the manuscript. All authors read and approved the final manuscript.

\section{Competing interests}

The authors declare that they have no competing interests.

Received: 14 September 2010 Accepted: 15 October 2010

Published: 15 October 2010

\section{References}

1. Jones MS, Kapoor A, Lukashov W, Simmonds P, Hecht F, Delwart E: New DNA viruses identified in patients with acute viral infection syndrome. J Virol 2005, 79:8230-8236.

2. Lau SK, Woo PC, Tse H, Fu CT, Au WK, Chen XC, Tsoi HW, Tsang TH, Chan JS, Tsang DN, Li KS, Tse CW, Ng TK, Tsang OT, Zheng BJ, Tam S, Chan $\mathrm{KH}$, Zhou B, Yuen $\mathrm{KY}$ : Identification of novel porcine and bovine parvoviruses closely related to human parvovirus 4. J Gen Virol 2008, 89:1840-1848.

3. Fryer JF, Delwart E, Bernardin F, Tuke PW, Lukashov W, Baylis SA: Analysis of two human parvovirus PARV4 genotypes identified in human plasma for fractionation. J Gen Virol 2007, 88:2162-2167.

4. Simmonds P, Douglas J, Bestetti G, Longhi E, Antinori S, Parravicini C, Corbellino M: A third genotype of the human parvovirus PARV4 in subSaharan Africa. J Gen Virol 2008, 89:2299-2302.

5. Sharp CP, Lail A, Donfield S, Simmomns R, Leen C, Klenerman P, Delwart E, Gomperts ED, Simmonds P: High frequency of exposure to the novel human parvovirus PARV4 in hemophiliacs and injection drug users, as detected by a serological assay for PARV4 antibodies. J Infect Dis 2009, 200:119-125.

6. Fryer JF, Kapoor A, Minor PD, Delwart E, Baylis SA: Novel parvovirus and related variant in human plasma. Emerg Infect Dis 2006, 12:151-154.

7. Fryer JF, Hubbard AR, Baylis SA: Human parvovirus PARV4 in clotting factor VIII concentrates. Vox Sang 2007, 93:341-347.

8. Fryer JF, Delwart E, Hecht FM, Bernardin F, Jones MS, Shah N, Baylis SA: Frequent detection of the parvoviruses, PARV4 and PARV5, in plasma 
from blood donors and symptomatic individuals. Transfusion 2007, 47:1054-1061.

9. Lurcharchaiwong W, Chieochansin T, Payungporn S, Theamboonlers A, Poovorawan Y: Parvovirus 4 (PARV4) in serum of intravenous drug users and blood donors. Infection 2008, 36:488-491.

10. Simmonds P, Manning A, Kenneil R, Carnie FW, Bell JE: Parenteral transmission of the novel human parvovirus PARV4. Emerg Infect Dis 2007, 13:1386-1388.

11. Manning A, Russell V, Eastick K, Leadbetter GH, Hallam N, Templeton $K_{\text {, }}$ Simmonds P: Epidemiological profile and clinical associations of human bocavirus and other human parvoviruses. J Infect Dis 2006, 194:1283-1290.

12. Manning A, Willey SJ, Bell JE, Simmonds P: Comparison of tissue distribution, persistence, and molecular epidemiology of parvovirus B19 and novel human parvoviruses PARV 4 and human bocavirus. I Infect Dis 2007, 195:1345-1352.

13. Schneider B, Fryer JF, Reber U, Fischer HP, Tolba RH, Baylis SA, EisHübinger AM: Persistence of novel human parvovirus PARV4 in liver tissue of adults. J Med Virol 2008, 80:345-351.

14. Botto S, Bergallo M, Sidoti F, Terlizzi ME, Astegiano S, Ponti R, Costa C, Cavallo R: Detection of PARV4, genotypes 1 and 2, in healthy and pathological clinical specimens. New Microbiol 2009, 32:189-192.

15. Corcioli F, Zakrzewska K, Rinieri A, Fanci R, Innocenti M, Civinini R, De Giorgi V, Di Lollo S, Azzi A: Tissue persistence of parvovirus B19 genotypes in asymptomatic persons. J Med Virol 2008, 80:2005-2011.

16. Longhi E, Bestetti G, Acquaviva V, Foschi A, Piolini R, Meroni L, Magni C, Antinori S, Parravicini C, Corbellino M: Human parvovirus 4 in the bone marrow of Italian patients with AIDS. AIDS 2007, 21:1481-1483.

17. Lotze U, Egerer R, Glück B, Zell R, Sigusch H, Erhardt C, Heim A, Kandolf $R$, Bock T, Wutzler P, Figulla HR: Low level myocardial parvovirus B19 persistence is a frequent finding in patients with heart disease but unrelated to ongoing myocardial injury. J Med Virol 2010, 82:1449-1457.

18. Mogensen TH, Jensen JMB, Hamilton-Dutoit S, Larsen CS: Chronic hepatitis caused by persistent parvovirus B19 infection. BMC Infect Dis 2010, 10:246.

19. Wang C, Heim A, Schlaphoff $V$, Suneetha PV, Stegmann KA, Jiang H, Krueger M, Fytili P, Schulz T, Cornberg M, Kandolf R, Manns MP, Bock CT, Wedemeyer H: Intrahepatic long-term persistence of parvovirus B19 and its role in chronic viral hepatitis. J Med Virol 2009, 81:2079-2088.

20. Kühl U, Pauschinger M, Bock T, Klingel K, Schwimmbeck CP, Seeberg B, Krautwurm L, Poller W, Schultheiss HP, Kandolf R: Parvovirus B19 infection mimicking acute myocardial infarction. Circulation 2003, 108:945-950.

21. Liu SC, Tsai CT, Wu CK, Yu MF, Wu MZ, Lin LI, Wang SS, Hwang JJ, Tseng YZ, Chiang FT, Tseng CD: Human parvovirus B19 infection in patients with coronary atherosclerosis. Arch Med Res 2009, 40:612-617.

doi:10.1186/1743-422X-7-272

Cite this article as: Corcioli et al:: Human parvovirus PARV4 DNA in tissues from adult individuals: a comparison with human parvovirus B19 (B19V). Virology Journal 2010 7:272.

\section{Submit your next manuscript to BioMed Central and take full advantage of:}

- Convenient online submission

- Thorough peer review

- No space constraints or color figure charges

- Immediate publication on acceptance

- Inclusion in PubMed, CAS, Scopus and Google Scholar

- Research which is freely available for redistribution

Submit your manuscript at www.biomedcentral.com/submit
Ciomed Central 